Title: Commentary on Kerr et al (2017): More evidence that social and health limitations in childhood increase the risk of lifetime abstention from alcohol

LINDA NG FAT, PH.D., ${ }^{a^{*}}$

${ }^{a}$ Department of Epidemiology \& Public Health, Institute of Epidemiology \& Health Care, University

College London, London, England. Tel: 00442076798235

*Correspondence may be sent to Linda Ng Fat at the above address or via email at: 1.ngfat@ucl.ac.uk

\title{
Conflict of interests:
}

None

\section{Sources of Funding:}

This research received no specific grant from any funding agency in the public, commercial or not-for-profit sectors.

\section{Acknowledgement:}

This commentary was based on findings from a completed doctorate, joint funded by Alcohol Research UK and UCL Impact. 


\section{Commentary on Kerr et al (2017): More evidence that social and health limitations in childhood increase the risk of lifetime abstention from alcohol}

Childhood poverty and work-related health limitations were found to increase the risk of being a lifetime abstainer from alcohol, according to a new study by Kerr and colleagues(Kerr et al., 2017). Findings were based on analyses of the 1979 National Longitudinal Survey of Youth Cohort, a nationally representative prospective study following 6,111 youths aged 14 to 21 in private residences in the US. Strengths of the study include a derivation of lifetime abstention based on successive information since youth up to age 55, meaning lifetime abstention was not subject to validity or recall issues, as has been found with the identification of being a lifetime abstainer at a later time-point(Caldwell et al., 2006). Furthermore, this association did not differ for lifetime abstainers under a strict definition of no alcoholic drinks, and lifetime minimal drinkers, who drank three or fewer drinks in a month meaning even very occasional drinkers may be prone to a pre-existing poor health and social disadvantage bias. This association held after extensive adjustment for potential confounders including religion, ethnicity and having an alcoholic relative. Lifetime abstention has become a topic of interest to epidemiologists, since it was discovered that lifetime abstainers were a better referent group to compare with drinkers, in assessing the health effects of alcohol consumption, than non-drinkers. A broader non-drinker group in later life is likely to include former drinkers, who have been found to have pre-existing worse health overall, hence any non-drinking group that included former drinkers is likely to be subject to a 'sick-quitter' bias (Shaper et al., 1988). However this new study throws further doubts on the validity of even lifetime abstainers as a referent group.

Findings from Kerr et al (2017) (Kerr et al., 2017), add to the growing body of literature on lifetime abstention and abstention more generally. Several studies have found a social gradient in non-drinking(Jefferis et al., 2007; Ng Fat and Shelton, 2012), with the more 
socially and economically disadvantaged being less likely to drink alcohol. In terms of health, Kerr et al's (2017) findings are consistent with a different prospective study in the UK, which found limiting longstanding illness from an early age and persistent limiting longstanding illness from childhood to be associated with lifetime abstention (Ng Fat et al., 2014). Since this relationship was found early on in life, it suggests that poor health may be causing lifetime abstention, rather than the reverse, as has been implicated in later-life in comparison with moderate drinkers. More specifically Kerr et al (2017) found health related work limitations reported at age 14 to 21 to be associated with lifetime abstention. This may highlight a potential mechanism through which poor health may influence lifetime abstention, via the non-participation in the work-force. Indeed, this would be consistent with the social gradient in non-drinking. The transition from adolescence to adulthood may be a critical period in which youths are introduced to alcohol consumption, and having a health condition or not being part of a work force may be a barrier towards this.

\section{The J-curve still in question; there remains no conclusive evidence of a 'health benefit'}

\section{of alcohol}

The J-shaped curve, in which non-drinkers (and heavy drinkers) have worse health outcomes than moderate drinkers has been found in countless observational studies, which make claims that moderate alcohol consumption is beneficial for health appear so convincing. However, a concurrent body of literature is now emerging on risk factors for lifetime abstention from alcohol. Early life poverty and limiting illness, has been found to be related to lifetime abstention in two British Cohorts (Ng Fat et al., 2014) and now in the US (Kerr et al., 2017). Early life disadvantage can increase the risk of mortality and morbidity in later life (Galobardes et al., 2006; Korkeila et al., 2010; Kuh et al., 2002). This suggests strong selection effects into lifetime abstention. This throws further doubts on the J-curve, over and above misclassification errors that were found by Stockwell and colleagues in most 
observational studies that find J-curves, which tend to overestimate the health benefits of alcohol (Stockwell et al., 2016).

Could selection effects into lifetime abstention explain why findings from observational studies tend to contradict emerging evidence from Mendelian Randomisation studies, which find no evidence that moderate alcohol has health benefits? This has been found in relation to CVD (the most studied condition in which alcohol consumption and its relative risk appears to be J-curved) (Holmes et al., 2014) and cognitive decline (Kumari et al., 2014). Mendelian Randomisation studies, unlike observational studies, are not subject to the same limitations of residual confounding, and therefore are considered a superior method for examining causality. A selection effect into life abstention could potentially explain why a presumed 'health benefit' of alcohol has been ascribed to numerous conditions based on studies using observational data, and to a broad demographic, when a health benefit for CVD has been suggested to apply to women in middle-age only. While the mechanism for a protective effect on CVD via raising good HDL cholesterol put forward sounds plausible (although whether HDL cholesterol is protective of CVD has recently been contested (Voight et al.)), for other conditions where a J-shaped relationship has been found, the causal mechanism is less clear. Conditions in which alcohol consumption and relative risk of the condition have a J-curved pattern are far reaching including osteoporosis, cognitive functioning, and mortality. Fekjær in his critical analyses found a presumed health benefit from alcohol across 24 different conditions including low birth rate, and the common cold (Fekjær, 2013).

A pre-existing poor health bias could explain many of these findings. For example, rates of physical and mental disability, were found to be higher among non-drinkers compared to drinkers in adolescence (Ng Fat et al., 2014), which could increase the risk of osteoporosis later on in life, via several pathways including immobility. Poorer mental health (Lucas et al., 2010), including anxiety and depression in early adulthood ( $\mathrm{Ng}$ Fat and Shelton, 2012), 
which is more common in non-drinkers than moderate drinkers, could increase the risk of cognitive decline and dementia in later life, as studies have found the cumulative effects of depression throughout life to be a significant risk factor (Zeki Al Hazzouri et al., 2013). A lack of social support ( $\mathrm{Ng}$ Fat et al., 2016) has also been found among non-drinkers compared to drinkers, which could increase the risk of mortality. Lack of social relationships has been found to increase the risk of mortality on a par with other traditional risk factors such as smoking (Holt-Lunstad et al., 2010). Poorer health and social economic disadvantage from childhood into adulthood, could impact on ageing and overall mortality via several mechanisms (Kuh et al., 2002).

Lifetime abstainers appear more disadvantaged than the average person, even early on in life. Could it be that the group who are lifetime abstainers are in effect pooling together the most disadvantaged in terms of health and economic status? Drinking alcohol is the norm in many societies, often used as an accompaniment to celebrations, holidays, social gatherings, work events and more. This is illustrated through lifetime abstainers accounting for only a small minority of the population, around $1.7 \%$ under the strict definition in the US study (Kerr et al., 2017), and between 1.4-2.2\% in the UK (Ng Fat et al., 2014). Those with extreme physical ailments and disabilities are likely to be excluded from mainstream society including the workforce, which may serve as a barrier towards participating in some mainstream social activities or venues, which involve the consumption of alcohol. In other words lifetime abstainers may be the most socially excluded, given how much of drinking alcohol occurs within a social context this is plausible. Indeed this would be consistent with the limiting component of illness found to be associated with lifetime abstention, as in the study by Kerr et al (2017) using 'health related work limitations', and with 'limiting longstanding illness' in the UK (Ng Fat et al., 2014). Alternatively poorer physical health may directly influence the 
non-consumption of alcohol, since alcohol may interact with medications, or increase the risk of accidents to those who may be already vulnerable.

\section{What can be done if lifetime abstainers are the only alternative to use as a referent group?}

The authors conclude from this study that epidemiologists wishing to explore the effects of drinking alcohol compared with abstaining ought to adjust for early life adversity and childhood health. It would be interesting to observe whether the J-curved relationship would remain using lifetime abstainers, following this adjustment. One study, in exploring the effect of alcohol consumption at age 33 on mortality, did manage to adjust for a range of possible confounders from early life including early life social economic circumstances, physical health and adult social support(Evans-Polce et al., 2016). Evans-Polce et al (2016) found that early life poor physical health explained some of the increased risk of mortality among abstainers compared to light drinkers at age 33, but not all the difference, as an elevated risk of mortality remained even after these extensive adjustments. Crucially, this applied to abstainers at age 33 who had been former drinkers at age 23 only, and not to lifetime abstainers who reported abstaining at age 23 and 33 suggesting that "long-term abstention from alcohol did not confer increased mortality risk" (p.77). It is possible that an elevated risk of mortality among abstainers compared to light drinkers at age 33 following these extensive adjustments, was due to the inclusion of former drinkers in this group and their past use of alcohol. Unfortunately no information on past drinking behaviour of former drinkers at age 33 was provided to verify this, and numbers were too small to examine the exact cause of death.

The final nail in the coffin on whether there is a health benefit from alcohol consumption is unlikely to come from observational studies, due to the problems related to residual 
confounding. However if more studies such as the one carried out by Evans-Polce et al (2016) emerge which are able to adjust for early life factors, this may shed some light on whether there has been a fundamental source of bias. In practice, many datasets using middleage cohorts fail to have information on early life poverty and health as this requires a long period of data collection. In these cases where early life information is not available, a strong caveat must be considered when using lifetime abstainers as a referent group. It has been suggested that occasional drinkers may be a better alternative, accounting for a larger proportion of people (9.7\%) than strict lifetime abstainers in the study by Kerr et al (2017); however this study also found lifetime occasional minimal drinkers to have similar characteristics to strict lifetime abstainers therefore caution must still be heeded. Given that the comparison between drinkers and non-drinkers is fraught with errors, and evidence that any amount of alcohol increases your risk of certain cancers (Bagnardi et al., 2015) any overall health benefit of drinking alcohol would be hard to weigh up against the consequences. Perhaps it is time to shift our attention to the other end of the J-curve, where the relative risk of morbidity increases with heavier consumption after an upper limit of consumption, quantifying the exact risks. After all, this is where alcohol-related harm can be reduced.

\section{References}

Bagnardi V, Rota M, Botteri E, Tramacere I, Islami F, Fedirko V, Scotti L, Jenab M, Turati F, Pasquali E, Pelucchi C, Galeone C, Bellocco R, Negri E, Corrao G, Boffetta P, La Vecchia C (2015) Alcohol consumption and site-specific cancer risk: a comprehensive dose-response meta-analysis. $\mathrm{Br}$ J Cancer 112(3):580-93. 
Caldwell TM, Rodgers B, Power C, Clark C, Stansfeld SA (2006) Drinking histories of self-identified lifetime abstainers and occassinoal drinkers: findings from the 1958 Brtisih Birth Cohort Study. Alcohol \& Alcoholism 41(6):650-654.

Evans-Polce RJ, Staff J, Maggs JL (2016) Alcohol abstention in early adulthood and premature mortality: Do early life factors, social support, and health explain this association? Social Science \& Medicine 163:71-79.

Fekjær HO (2013) Alcohol-a universal preventive agent? A critical analysis. Addiction 108(12):20512057.

Galobardes B, Smith GD, Lynch JW (2006) Systematic Review of the Influence of Childhood Socioeconomic Circumstances on Risk for Cardiovascular Disease in Adulthood. Annals of Epidemiology 16(2):91-104.

Holmes MV, Dale CE, Zuccolo L, Silverwood RJ, Guo Y, Ye Z, Prieto-Merino D, Dehghan A, Trompet S, Wong A, Cavadino A, Drogan D, Padmanabhan S, Li S, Yesupriya A, Leusink M, Sundstrom J, Hubacek JA, Pikhart H, Swerdlow DI, Panayiotou AG, Borinskaya SA, Finan C, Shah S, Kuchenbaecker KB, Shah T, Engmann J, Folkersen L, Eriksson P, Ricceri F, Melander O, Sacerdote C, Gamble DM, Rayaprolu S, Ross OA, McLachlan S, Vikhireva O, Sluijs I, Scott RA, Adamkova V, Flicker L, Bockxmeer FMv, Power C, Marques-Vidal P, Meade T, Marmot MG, Ferro JM, Paulos-Pinheiro S, Humphries SE, Talmud PJ, Leach IM, Verweij N, Linneberg A, Skaaby T, Doevendans PA, Cramer MJ, Harst Pvd, Klungel OH, Dowling NF, Dominiczak AF, Kumari M, Nicolaides AN, Weikert C, Boeing H, Ebrahim S, Gaunt TR, Price JF, Lannfelt L, Peasey A, Kubinova R, Pajak A, Malyutina S, Voevoda MI, Tamosiunas A, Maitland-van der 
Zee AH, Norman PE, Hankey GJ, Bergmann MM, Hofman A, Franco OH, Cooper J, Palmen J, Spiering W, Jong PAd, Kuh D, Hardy R, Uitterlinden AG, Ikram MA, Ford I, Hyppönen E, Almeida OP, Wareham NJ, Khaw K-T, Hamsten A, Husemoen LLN, Tjønneland A, Tolstrup JS, Rimm E, Beulens JWJ, Verschuren WMM, Onland-Moret NC, Hofker MH, Wannamethee SG, Whincup PH, Morris R, Vicente AM, Watkins H, Farrall M, Jukema JW, Meschia J, Cupples LA, Sharp SJ, Fornage M, Kooperberg C, LaCroix AZ, Dai JY, Lanktree MB, Siscovick DS, Jorgenson E, Spring B, Coresh J, Li YR, Buxbaum SG, Schreiner PJ, Ellison RC, Tsai MY, Patel SR, Redline S, Johnson AD, Hoogeveen RC, Hakonarson H, Rotter JI, Boerwinkle E, Bakker PIWd, Kivimaki M, Asselbergs FW, Sattar N, Lawlor DA, Whittaker J, Davey Smith G, Mukamal K, Psaty BM, Wilson JG, Lange LA, Hamidovic A, Hingorani AD, Nordestgaard BG, Bobak M, Leon DA, Langenberg C, Palmer TM, Reiner AP, Keating BJ, Dudbridge F, Casas JP (2014) Association between alcohol and cardiovascular disease: Mendelian randomisation analysis based on individual participant data. vol 349.

Holt-Lunstad J, Smith TB, Layton JB (2010) Social Relationships and Mortality Risk: A Meta-analytic Review. PLoS Med 7(7):e1000316.

Jefferis BJMH, Manor O, Power C (2007) Social gradients in binge drinking and abstaining: trends in a cohort of British adults. Journal of Epidemiology Community Health 61:150-153.

Kerr WC, Lui CK, Williams E, Ye Y, Greenfield TK, Lown EA (2017) Health Risk Factors Associated with Lifetime Abstinence from Alcohol in the 1979 National Longitudinal Survey of Youth Cohort. Alcoholism: Clinical and Experimental Research 41(2):388-398. 
Korkeila J, Vahtera J, Korkeila K, Kivimäki M, Sumanen M, Koskenvuo K, Koskenvuo M (2010) Childhood adversities as predictors of incident coronary heart disease and cerebrovascular disease. Heart 96(4):298-303.

Kuh D, Hardy R, Langeberg C, Richards M, Wadsworth M (2002) Mortality in adults aged 26-54 years related to socio-economic conditions in childhood and adulthood: a post war birth cohort study. British Medical Journal (325):1076-80.

Kumari M, Holmes MV, Dale CE, Hubacek J, Palmer TM, Pikhart H, Peasey A, Britton A, Horvat P, Kubinova R, Malyutina S, Pajak A, Tamosiunas A, Shanka A, Singh-Manoux A, Voevoda M, Kivimaki M, Hingorani AD, Marmot MG, Casas JP, Bobak M (2014) Alcohol Consumption and Cognitive Performance: a Mendelian Randomisation Study. Addiction:n/a-n/a.

Lucas N, Windsor TD, Caldwell TM, Rodgers B (2010) Psychological Distress in Non-Drinkers: Associations with Previous Heavy Drinking and Current Social Relationships. Alcohol and Alcoholism 45(1):95-102.

Ng Fat L, Cable N, Marmot M, Shelton N (2014) Persistent long-standing illness and non-drinking over time, implications for the use of lifetime abstainers as a control group. Journal of Epidemiology and Community Health 68(1):71-77.

Ng Fat L, Scholes S, Jivraj S (2016) The Relationship Between Drinking Pattern, Social Capital, and Area-Deprivation: Findings From the Health Survey for England. Journal of Studies on Alcohol and Drugs 78(1):20-29. 
Ng Fat L, Shelton N (2012) Associations between self-reported illness and non-drinking in young adults. Addiction 107(9):1612-1620.

Shaper AG, Wannamethee G, Walker M (1988) Alcohol and Mortality in British men: Explaining the U-shaped curve. The Lancet 332(8623):1267-1273.

Stockwell T, Zhao J, Panwar S, Roemer A, Naimi T, Chikritzhs T (2016) Do “Moderate" Drinkers Have Reduced Mortality Risk? A Systematic Review and Meta-Analysis of Alcohol Consumption and All-Cause Mortality. Journal of Studies on Alcohol and Drugs 77(2):185-198.

Voight BF, Peloso GM, Orho-Melander M, Frikke-Schmidt R, Barbalic M, Jensen MK, Hindy G, Hólm H, Ding EL, Johnson T, Schunkert H, Samani NJ, Clarke R, Hopewell JC, Thompson JF, Li M, Thorleifsson G, Newton-Cheh C, Musunuru K, Pirruccello JP, Saleheen D, Chen L, Stewart AFR, Schillert A, Thorsteinsdottir U, Thorgeirsson G, Anand S, Engert JC, Morgan T, Spertus J, Stoll M, Berger K, Martinelli N, Girelli D, McKeown PP, Patterson CC, Epstein SE, Devaney J, Burnett M-S, Mooser V, Ripatti S, Surakka I, Nieminen MS, Sinisalo J, Lokki M-L, Perola M, Havulinna A, de Faire U, Gigante B, Ingelsson E, Zeller T, Wild P, de Bakker PIW, Klungel OH, Maitland-van der Zee A-H, Peters BJM, de Boer A, Grobbee DE, Kamphuisen PW, Deneer VHM, Elbers CC, Onland-Moret NC, Hofker MH, Wijmenga C, Verschuren WMM, Boer JMA, van der Schouw YT, Rasheed A, Frossard P, Demissie S, Willer C, Do R, Ordovas JM, Abecasis GR, Boehnke M, Mohlke KL, Daly MJ, Guiducci C, Burtt NP, Surti A, Gonzalez E, Purcell S, Gabriel S, Marrugat J, Peden J, Erdmann J, Diemert P, Willenborg C, König IR, Fischer M, Hengstenberg C, Ziegler A, Buysschaert I, Lambrechts D, Van de Werf F, Fox KA, El Mokhtari NE, Rubin D, Schrezenmeir J, Schreiber S, Schäfer A, Danesh J, Blankenberg S, Roberts R, 
McPherson R, Watkins H, Hall AS, Overvad K, Rimm E, Boerwinkle E, Tybjaerg-Hansen A, Cupples LA, Reilly MP, Melander O, Mannucci PM, Ardissino D, Siscovick D, Elosua R, Stefansson K, O'Donnell CJ, Salomaa V, Rader DJ, Peltonen L, Schwartz SM, Altshuler D, Kathiresan S Plasma HDL cholesterol and risk of myocardial infarction: a mendelian randomisation study. The Lancet 380(9841):572-580.

Zeki Al Hazzouri A, Vittinghoff E, Byers A, Covinsky K, Blazer D, Diem S, Ensrud KE, Yaffe K (2013) Long-term Cumulative Depressive Symptom Burden and Risk of Cognitive Decline and Dementia Among Very Old Women. J Gerontol A Biol Sci Med Sci. 